\title{
Effectiveness of Silorane-based Composite as a Repair Filling for Dimethacrylate- or Silorane-based Composite Restorations
}

Daphne Camara Barcellos, Patrícia Rondon Pleffken, César Rogério Pucci, Clovis Pagani

Sergio Eduardo de Paiva Gonçalves, Carlos Rocha Gomes Torres

\section{ABSTRACT}

Objective: This study aimed to evaluate the suitability of one specific silorane-based composite for the application as a repair material for different substrates.

Materials and methods: Truncated cones of composites fabricated and thermocycled for 6000 cycles to serve as a substrate were made of two commercially available dimethacrylate-based composites (DBC) (Filtek Supreme and Clearfil APX) and one silorane-based composite (SBC) (Filtek $\mathrm{P90}$ ). The surface of the specimens was treated with air-abraded using $\mathrm{Al}_{2} \mathrm{O}_{3}$-particles of $50 \mu \mathrm{m}$ size. A Teflon device was used to fabricate inverted truncated cones of repair composite over the surface-treated top of each original truncated cone. DBC and SBC were used as repair materials and bonded to the specimens using either a dimethacrylate-based (single bond 2) or a phosphate-methacrylate-based (adhesive belongs to the silorane) adhesives. The specimens were stored in distilled water at $37^{\circ} \mathrm{C}$ for 7 days and stressed to failure under tension. The data were analyzed with one-way ANOVA and Tukey tests at $5 \%$.

Results: Bonding DBC as a repair material to a $\mathrm{DBC}$ substrate using the dimethacrylate-based adhesive produced the highest bond strength. Bonding DBC as repair material using the phosphate-methacrylate-based adhesive or SBC as repair material using the dimethacrylate-based adhesive produced lower bond strength, regardless the brand and of the chemical formulation of the aged substrate.

Conclusion: In order to obtain high bond strength, there is need to match adhesive and repair material, regardless the brand and of the chemical formulation of the substrate.

Keywords: Composite, Silorane, Adhesion, Bond strength.

How to cite this article: Barcellos DC, Pleffken PR, Pucci CR, Pagani C, Gonçalves SEP, Torres CRG. Effectiveness of Silorane-based Composite as a Repair Filling for Dimethacrylate- or Silorane-based Composite Restorations. World J Dent 2012;3(2):161-65.

\section{Source of support: Nil}

Conflict of interest: None declared

\section{INTRODUCTION}

Failure or fracture defects of composite restorations should be first evaluated for the possibility of repair procedure stead a complete replacement of a filling, ${ }^{1}$ because repair procedure is considered as a more conservative approach and a minimal invasive alternative than it complete removal and remake. ${ }^{2}$

Combinations of surface treatments and bonding agents influence the bond strength of the repaired dimethacrylatebased composites. ${ }^{3,4}$ Junior et $\mathrm{al}^{5}$ (2008) observed that the use of aluminium oxide sandblasting on the aged composite surface enhances the shear-bond strength of repaired dimethacrylate-based composites. Application of a thin layer of bonding agent on the aged composite surface increased significantly the tensile strength of the repair procedure. ${ }^{7}$ Also, the roughening of filling surfaces associated to application of a low-viscosity resin enhance the repair bond strengths. ${ }^{3,4}$

Padipatvuthiku ${ }^{14}$ (2007) suggests that the mechanisms of adhesion of repair procedure promoted by resin-based bonding agents can be due to the micromechanical retention through monomer penetration into surface irregularities; and due to the chemical bond formation promoted by solvents in the adhesive systems. ${ }^{3,4}$ The solvents can cause swelling and gelation of the surface layer, allowing the monomer penetrate to the unconverted vinyl groups $(-\mathrm{C}=\mathrm{C})$ in the aged composite subsurface. ${ }^{2,4}$ However, most authors 'repaired' the original composite with composites with same chemical formulation (dimethacrylate-based).

Recently, silorane-based composite (SBC) (Filtek Silorane, 3M ESPE Dental Products) was introduced in the dental market. The monomer system consists a functional epoxy groups that contain both siloxane and oxirane structural moieties (i.e. 'silorane') using ring opening polymerization of the silorane molecules. ${ }^{6,7}$ This composite was designed to reduce shrinkage stress and cuspal deflection $^{8,9}$ associated with conventional dimethacrylatebased composite (DBC).

It should be important to note the compatibility of composites with different chemical formulation, when repair procedure is indicated. Also, it is necessary to define a repair protocol between DBCs and SBCs. The aim of this study was to evaluate the suitability of one specific silorane-based composite for the application as a repair material for different substrates. 


\section{MATERIALS AND METHODS}

The materials used in this study are listed in Table 1.

A two-piece Teflon device was used to prepare truncated cones of composites fabricated to serve as a substrate of two commercially available DBCs (Filtek Supreme and Clearfil APX, shade A3) and one SBC (Filtek P90, shade A3). Each truncated cone measured $4 \mathrm{~mm}$ in height, with the bottom being $4 \mathrm{~mm}$ in diameter and the top being $2 \mathrm{~mm}$ in diameter. The composites were inserted in the Teflon device in $2 \mathrm{~mm}$ thick increments. Each composite increment was polymerized for 20 seconds with a light curing unit (XL 3000, 3M ESPE) at an output intensity of $500 \mathrm{~mW} / \mathrm{cm}^{2}$.

One hundred and thirty-five truncated resin composite cones were prepared and stored in distilled water at $37^{\circ} \mathrm{C}$ for 7 days. The truncated cones were thermal-cycled for 6,000 cycles at a temperature ranging between $5^{\circ} \mathrm{C}$ and $55^{\circ} \mathrm{C}$ $\left( \pm 2^{\circ} \mathrm{C}\right)$, with a dwell time of 30 seconds, followed by storage in distilled water at $37^{\circ} \mathrm{C}$ for another 24 hours.

The surface of the piece of composites was air-abraded using $\mathrm{Al}_{2} \mathrm{O}_{3}$-particles of $50 \mu \mathrm{m}$ size ${ }^{4}$ according to the manufacturer's recommendations (Microetcher ERC, Danville Engineering, California, USA). DBC and SBC were used as repair materials and bonded to the surface of the piece of composites air-abraded using either a dimethacrylate-based (single bond 2 adhesive system, 3M ESPE) or a phosphate-methacrylate-based (silorane system adhesive bond, 3M ESPE — adhesive belongs to the silorane) adhesives.

A Teflon device was used to fabricate an inverted truncated cone of repair composite over the surface-treated top of each original aged truncated cone, using incremental applications, with each layer polymerized separately for 20 seconds. The final specimen consisted of two inverted

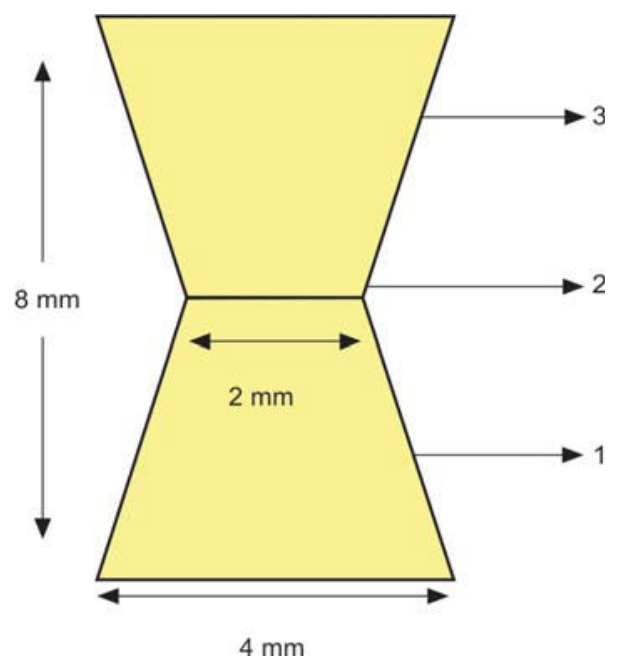

Fig. 1A: Dimensions of the specimen: (1) Aged substrate; (2) Repair procedure (interface); (3) Fresh composite

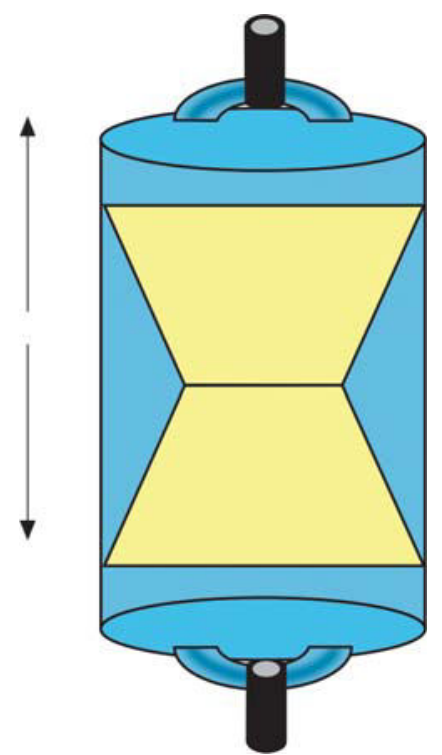

Fig. 1B: Schematic diagram of the tensile test

Table 1: The materials used in this study

\begin{tabular}{|c|c|c|}
\hline Material & Manufacturer & Composition \\
\hline $\begin{array}{l}\text { Adper single } \\
\text { bond } 2 \text { adhesive system }\end{array}$ & 3M ESPE, St Paul, MN, USA & $\begin{array}{l}\text { Bis-GMA (bisphenol-a-glycidyl dimethacrylate), HEMA } \\
\text { (2-hydroxyethyl methacrylate), dimethacrylate, } \\
\text { methacrylate functional copolymer of polyacrylic and } \\
\text { polytaconic acid, water, alcohol, photoinitiator }\end{array}$ \\
\hline $\begin{array}{l}\text { Silorane system } \\
\text { adhesive bond }\end{array}$ & 3M ESPE, St Paul, MN, USA & $\begin{array}{l}\text { TEGDMA (triethylene glycol dimethacrylate), phosphoric } \\
\text { acid methacryloxy-hexylesters, 16-hexanediol } \\
\text { dimethacrylate }\end{array}$ \\
\hline Filtek Supreme & 3M ESPE, St Paul, MN, USA & $\begin{array}{l}\text { BIS-GMA, BIS-EMA (Bisphenol A polyethylene glycol } \\
\text { diether dimethacrylate), UDMA (urethane } \\
\text { dimethacrylate), TEGDMA. Nonagglomerated/non- } \\
\text { aggregated } 75 \mathrm{~nm} \text { silica nanofiller, agglomerate silica } \\
\text { nanocluster silica nanoparticles of } 75 \mathrm{~nm}\end{array}$ \\
\hline Filtek P90 & 3M ESPE, St Paul, MN, USA & $\begin{array}{l}\text { 3,4-epoxycyclohexylethylcyclo-polymethylsiloxane } \\
\text { (5-15 wt\%), bis-3,4-epoxycyclohexylethyl-phenylmethylsilane } \\
(5-15 \mathrm{wt} \%) \text {, silanized quartz (50-70 wt\%), yttrium fluoride } \\
(10-20 \mathrm{wt} \%)\end{array}$ \\
\hline Clearfil APX & Kuraray Co., Ltd, Japan & $\begin{array}{l}\text { Bis-GMA, TEGDMA, silanated barium glass filler, } \\
\text { silanated silica filler, silanated colloidal silica, } \\
\text { dl-camphorquinone, catalysts, accelerators, pigments }\end{array}$ \\
\hline
\end{tabular}


Table 2: Experimental groups evaluated in this study

\begin{tabular}{llll}
\hline Group & Substrate & Intermediate layer (adhesive) & Composite repair \\
\hline 1 (control dimethacrylate) & $\begin{array}{l}\text { Dimethacrylate } \\
\text { (Filtek supreme) }\end{array}$ & Dimethacrylate-based & $\begin{array}{l}\text { Dimethacrylate } \\
\text { (Filtek Supreme) }\end{array}$ \\
2 (control silorane) & Silorane (Filtek P90) & Phosphate-methacrylate-based & Silorane (Filtek P90) \\
3 & Silorane (Filtek P90) & Dimethacrylate-based & Silorane (Filtek P90) \\
4 & Dimethacrylate (ClearFil APX) & Phosphate-methacrylate-based & Silorane (Filtek P90) \\
5 & Dimethacrylate (Filtek supreme) & Phosphate-methacrylate-based & Silorane (Filtek P90) \\
6 & Silorane (Filtek P90) & Phosphate-methacrylate-based & Dimethacrylate (Filtek Supreme) \\
7 & Silorane (Filtek P90) & Phosphate-methacrylate-based & Dimethacrylate (ClearFil APX) \\
8 & Dimethacrylate (Filtek Supreme) & Dimethacrylate-based & Silorane (Filtek P90) \\
9 & Dimethacrylate (ClearFil APX) & Dimethacrylate-based & Silorane (Filtek P90) \\
\hline
\end{tabular}

truncated cones of resin composites united by their circular top surfaces, where the repair was made (Fig. 1A). ${ }^{10}$

Fifteen specimens for each group were prepared (Table 2). The specimens were stored in distilled water at $37^{\circ} \mathrm{C}$ for 7 days. $^{2}$

The specimens were stress to failure (Fig. 1B) under tension using a universal testing machine (Emic DL 2000, São José dos Pinhais, PR, Brazil) with a load cell of $50 \mathrm{kgf}$ at $1 \mathrm{~mm} / \mathrm{min}$.

After the tensile test, the specimens were analyzed with a 20× stereomicroscope (Stemi 2000, Karl Zeiss, Germany). Fractures were classified as cohesive in the substrate, adhesive at the interface or cohesive in the adherend.

Repair bond strengths (in MPa) derived from the nine groups were first examined to evaluate the normality (Shapiro-Wilk test) and homoscedasticity (modified Levene test) of the acquired data. As those assumptions did not appear to have been violated, the data was further analyzed using one-way ANOVA and Tukey multiple comparison tests. Statistical significance for all tests were preset at $\alpha=0.05$.

\section{RESULTS}

A highly significant difference $(\mathrm{p}=0.0000 ; \mathrm{F}=288$; $\mathrm{DF}=8$ ) was detected among the repair bond strengths of the nine groups. Pairwise comparisons of the repair bond strengths are shown in Table 3. Group 1 (control dimethacrylate-DBC substrate and dimethacrylate-based adhesive and $\mathrm{DBC}$ restoration) exhibited the highest repair strength which was not significantly different $(\mathrm{p}>0.05)$ from the groups 4 and 5 (DCB substrate plus phosphatemethacrylate-based adhesive and $\mathrm{SBC}$ restoration) and Group 2 (control silorane-SBC substrate and phosphatemethacrylate-based adhesive and SBC restorarion). The repair strength of groups 8 and 9 (DBC substrate and dimethacrylate-based adhesive and SBC restoration), Groups 7 and 6 (SBC substrate and phosphate-methacrylatebased adhesive and $\mathrm{DBC}$ restoration) and group 3 (SBC substrate and dimethacrylate-based adhesive and SBC restoration) was lower statistically different from those derived from groups 1, 2, 4 and 5 .

Table 3: Tensile bond strength (MPa) means and standard deviations of the groups

\begin{tabular}{|c|c|c|c|c|c|}
\hline Groups & Substrate & Intermediate layer (adhesive) & Composite repair & $\begin{array}{l}\text { Mean in } M P a \\
\quad( \pm S D)\end{array}$ & $\begin{array}{l}\text { Homogene- } \\
\text { ous sets* }\end{array}$ \\
\hline 1 & $\begin{array}{l}\text { Dimethacrylate } \\
\text { (Filtek Supreme) }\end{array}$ & Dimethacrylate-based & $\begin{array}{l}\text { Dimethacrylate } \\
\text { (Filtek Supreme) }\end{array}$ & $20.98( \pm 2.24)$ & $A$ \\
\hline 5 & $\begin{array}{l}\text { Dimethacrylate } \\
\text { (Filtek Supreme) }\end{array}$ & Phosphate-methacrylate-based & Silorane (Filtek P90) & $19.71( \pm 2.17)$ & $A$ \\
\hline 4 & $\begin{array}{l}\text { Dimethacrylate } \\
\text { (ClearFil APX) }\end{array}$ & Phosphate-methacrylate-based & Silorane (Filtek P90) & $19.51( \pm 1.61)$ & $A$ \\
\hline 2 & Silorane (Filtek P90) & Phosphate-methacrylate-based & Silorane (Filtek P90) & $19.45( \pm 2.38)$ & $A$ \\
\hline 9 & $\begin{array}{l}\text { Dimethacrylate } \\
\text { (ClearFil APX) }\end{array}$ & Dimethacrylate-based & Silorane (Filtek P90) & $4.44( \pm 2.19)$ & B \\
\hline 6 & Silorane (Filtek P90) & Phosphate-methacrylate-based & $\begin{array}{l}\text { Dimethacrylate } \\
\text { (Filtek Supreme) }\end{array}$ & $4.41( \pm 1.02)$ & B \\
\hline 8 & $\begin{array}{l}\text { Dimethacrylate } \\
\text { (Filtek Supreme) }\end{array}$ & Dimethacrylate-based & Silorane (Filtek P90) & $3.88( \pm 1.67)$ & B \\
\hline 3 & Silorane (Filtek P90) & Dimethacrylate-based & Silorane (Filtek P90) & $3.54( \pm 1.46)$ & B \\
\hline 7 & Silorane (Filtek P90) & Phosphate-methacrylate-based & $\begin{array}{l}\text { Dimethacrylate } \\
\text { (ClearFil APX) }\end{array}$ & $3.53( \pm 1.43)$ & B \\
\hline
\end{tabular}

SD: Standard of deviation; *The groups with the same letters show no significant differences 
Examination of specimens after fracture indicated predominantly adhesive fractures for all groups ( $>95 \%)$.

\section{DISCUSSION}

Two composites (Clearfil APX, Filtek Supreme) selected for repair ('substrate'), have dimethacrylate resin matrices (bis-GMA) but in differing amounts. One non-dimethacrylate hybrid material (Filtek P90 silorane composite) was selected, as the resin matrix is a ring-opening monomer. SBCs were developed for reduce problems of polymerization shrinkage, polymerization stress and water sorption. ${ }^{8,9}$ However, in case of the possibility of repair, a recent dilemma for the clinician is that composite monomers other than dimethacrylates (e.g. siloranes) are being used which require compatibility of materials differing in composition of matrix. Therefore, this study investigated the 'repairability' of composite restorations with different chemical formulation.

There is no consensus for the aging regimens simulating the oral conditions. In this study, 30 days short-term water storage followed by 6000 thermal cycles, then 24 hours water storage were used to obtain an aged substrate surface. ${ }^{1}$ The aging of the substrates has the purpose to simulate the clinical service changes that occurs in the filling, such as a decrease of unreacted methacrylate groups, water sorption and leaching of components. ${ }^{9,11}$

According to Ivanovas et al $(2010),{ }^{2}$ when DBC has aged processes, the number of available vinyl groups for crosspolymerization decrease. In this study, aged composite surface was roughening with aluminum oxide particle abrasion before adding intermediate layer (adhesive resin) to optimize repair bond strengths between aged composite substrate and fresh composite. ${ }^{5}$

The results of the present study indicated that the group 1 (control methacrylate-based), which was exclusively made of DBC (substrate and repair composite) with methacrylatebased intermediate layer, exhibited the highest repair strength. Values diminished in group 2 (control siloranebased), which was exclusively made of SBC (substrate and repair composite) with phosphate-methacrylate intermediate layer, however, the differences were not significant. Also, group 1 was not significantly different $(p>0.05)$ from the groups 4 and 5 which SBC with phosphate-methacrylate intermediate layer was used for repair on the aged methacrylate-based composite.

According to results of this study and based on the chemical similarity, the chemical connection between the $\mathrm{SBC}$ and Silorane system adhesive bond is more resistance and stable than the hypothesized bond between dimethacrylate-based adhesive and the SBC. The use of dimethacrylate-based intermediate layer and SBC repair material (groups 3, 8 and 9) or the use of phosphatemethacrylate intermediate layer and DBC repair material (groups 6 and 7) led to drastically decreased bond strengths compared to the groups 1,2, 4 and 5, regardless the brand and of the chemical formulation of the aged substrate. According to Maneenut et al ${ }^{12}$ (2010), Silorane system adhesive bond is designed as a bonding agent for use with SBC (Filtek P90); therefore, cannot be recommended for use with dimethacrylate-based composites, and conversely DBCs cannot be used with the Silorane system adhesive bond. ${ }^{12}$

Silorane system adhesive bond is not silorane-based but phosphate-dimethacrylate-based. Confirming results of this study, Tezvergil-Mutluay et $\mathrm{al}^{6}(2008)$ found an increase in shear bond strength between SBC and DBC using a phosphate-dimethacrylate-based intermediate resin compared to a dimethacrylate-based intermediate layer. Also, Moser et $\mathrm{al}^{13}$ (2009) observed that the use of a phosphate-dimethacrylate-based intermediate layer increases the shear bond strength of repairs between SBCs and DBCs.

However, Maneenut et $\mathrm{al}^{12}$ (2010) found that SBC repair material associated with the silane-based adhesive (Clearfil repair) showed highest bond strength then silorane system adhesive bond was used as an intermediate layer. According to Ivanovas et $\mathrm{al}^{2}$ (2010), mixed repairs do not produce lower bond strengths than repairs made of one sort of composite resin, SBC or DBC. They found that the mixed repairs with SBC and DBC using a silane coupling agent seem to be more reliable.

As emphasized by the manufacturers of Filtek P90 composite and Silorane system adhesive bond, their silorane system is chemically incompatible with dimethacrylate systems. Confirming the results of this study, TezvergilMutluay et $\mathrm{al}^{6}(2008)$ found that the bond strength between SBC and DBC without any intermediate resin showed lowest values compared silorane-silorane and dimethacrylatedimethacrylate combinations without intermediate layer.

Fracture pattern of specimens on all groups showed that there were predominantly adhesive fracture patterns along the aged substrate/intermediate layer/fresh composite. This result can be attributed to the microtensile test, suggested by Sano et al. ${ }^{14}$ They assess the tensile bond strength of specimens with small surface areas of the adhesive joint, where bond failures essentially occur at the adhesive interface. This method permits measurement of bond strengths of different test methods without cohesive failure.

If the clinician is unable to identify the present filling material, appropriate repair technique should be utilized. 
It is important to emphasize that a SBC repair material with a silorane-based adhesive intermediate layer should be used, and conversely DBC repair material with a dimethacrylatebased intermediate layer should be used to provide a satisfactory bond in repair procedures.

\section{CONCLUSION}

In order to bonding $\mathrm{DBC}$ as a repair material to a SBC substrate, a phosphate-methacrylate-based intermediate layer is required. In order to bonding $\mathrm{SBC}$ as a repair material to a DBC substrate, a dimethacrylate-based adhesive layer is required.

\section{REFERENCES}

1. Shawkat ES, Shortall AC, Addison O, Palin WM. Oxygen inhibition and incremental layer bond strengths of resin composites. Dent Mater 2009;25(11):1338-46.

2. Ivanovas S, Hickel R, Ilie N. How to repair fillings made by silorane-based composites. Clin Oral Investig 2010;15:915-22.

3. Hannig C, Laubach S, Hahn P, Attin T. Shear bond strength of repaired adhesive filling materials using different repair procedures. J Adhes Dent 2006;8:35-40.

4. Padipatvuthikul P, Mair LH. Bonding of composite to water aged composite with surface treatments. Dent Mater 2007;23:519-25.

5. Junior SA, Ferracane JL, Bona AD. Influence of surface treatments on the bond strength of repaired resin composite restorative materials. Dent Mater 2008;25:442-51.

6. Tezvergil-Mutluay Tezvergil A, Lassila LV, Vallittu PK. Incremental layers bonding of silorane composite: The initial bonding properties. J Dent 2008;36(7):560-63.

7. Weinmann W, Thalacker C, Guggenberger R. Siloranes in dental composites. Dent Mater 2005;21:68-74.

8. Eick JD, Kotha SP, Chappelow CC, Kilway KV, Giese GJ, Glaros AG, Pinzino CS. Properties of silorane-based dental resins and composites containing a stress-reducing monomer. Dent Mater 2007;23(8):1011-17.

9. Papacchini F, Magni E, Radovic I, Mazzitelli C, Monticellia F, Goracci C, et al. Effect of intermediate agents and pre-heating of repairing resin on composite-repair bonds. Oper Dent 2007;32:363-71.

10. Barcellos DC, Pucci CR, Torres CR, Goto EH, Inocencio AC. Effects of resinous monomers used in restorative dental modeling on the cohesive strength of composite resin. J Adhes Dent 2008;10:351-54.

11. Tezvergil A, Lassila LV, Vallittu PK. Composite-composite repair bond strength: Effect of different adhesion primers. J Dent 2003;31(8):521-25.
12. Maneenut C, Sakoolnamarka R, Tyas MJ. The repair potential of resin composite materials. Dent Mater 2010;27:e20-e27.

13. Moser S, Hickel R, Ilie N. Strength of aged repairs made by silorane- and dimethacrylate-based composites. J Dent Res 2008;87(Special Issue B): Abstract No. 0048.

14. Sano H, Shono T, Sonoda H, Takatsu T, Ciucchi B, Carvalho $\mathrm{R}$, Pashley DH. Relationship between surface area for adhesion and tensile bond strength evaluation of a micro-tensile bond test. Dent Mater 1994;10:236-40.

\section{ABOUT THE AUTHORS}

\section{Daphne Camara Barcellos}

MS, Postgraduate Student, Department of Restorative Dentistry, São José dos Campos School of Dentistry, São Paulo State University São Paulo, Brazil

\section{Patrícia Rondon Pleffken}

MS, Postgraduate Student, Department of Restorative Dentistry, São José dos Campos School of Dentistry, São Paulo State University, São Paulo Brazil

\section{César Rogério Pucci}

Assistant Professor, Department of Restorative Dentistry, São José dos Campos School of Dentistry, São Paulo State University, São Paulo Brazil

\section{Clovis Pagani}

Associate Professor, Department of Restorative Dentistry, São José dos Campos School of Dentistry, São Paulo State University, São Paulo Brazil

\section{Sergio Eduardo de Paiva Gonçalves}

Associate Professor, Department of Restorative Dentistry, São José dos Campos School of Dentistry, São Paulo State University, São Paulo, Brazil

\section{Carlos Rocha Gomes Torres}

Assistant Professor, Department of Restorative Dentistry, São José dos Campos School of Dentistry, São Paulo State University, São Paulo Brazil

\section{CORRESPONDING AUTHOR}

Carlos Rocha Gomes Torres, Assistant Professor, Department of Restorative Dentistry, Faculdade de Odontologia de São José dos Campos, Universidade do Estado de São Paulo, Avenida Engenheiro Francisco José Longo, 777, Jardim São Dimas, São José dos Campos, SP, CEP: 12245-000, Brazil, Phone: (12) 3947 9048, Fax: (12) 3947 9010, e-mail: carlosrgt@fosjc.unesp.br 
